\title{
Increased Awareness Needed for Inpatient Substance Use Disorder Treatment in Drug Use-Associated Infective Endocarditis
}

\author{
Alexandra E. Mihm, PharmD' (1), Mary C. Cash, PharmD Candidate', \\ Sarah A. Nisly, PharmD ${ }^{7,3}$, and Kyle A. Davis, PharmD ${ }^{7}$ \\ 'Department of Pharmacy, Wake Forest Baptist Medical Center, Winston-Salem, NC, USA; ${ }^{2}$ sshelman School of Pharmacy, University of North \\ Carolina, Chapel Hill, NC, USA; ${ }^{3}$ School of Pharmacy, Wingate University, Wingate, NC, USA.
}

$\mathrm{J}$ Gen Intern Med 35(7):2228-30

DOI: $10.1007 / \mathrm{s} 11606-019-05607-1$

(c) Society of General Internal Medicine 2019

\section{INTRODUCTION}

The incidence of drug use-associated infective endocarditis (DUA-IE) has increased in the USA, with North Carolina witnessing an extreme 12-fold increase in cases over the past decade. ${ }^{1}$ While patients are at increased risk of morbidity and mortality, inpatient IE management primarily focuses on treating the acute infection, leaving the underlying substance use disorder unaddressed. ${ }^{1,2}$ Utilization of substance abuse resources, including medication-assisted treatment (MAT), during inpatient treatment may prevent further abuse; minimize recurrent infections, readmissions, and mortality; and reduce healthcare costs. ${ }^{2,3}$ Much remains unknown surrounding patient characteristics and resources offered during hospitalization for DUA-IE and the impact of resources on patient outcomes. The objective of this study was to describe and evaluate substance abuse resources offered during inpatient DUA-IE treatment.

\section{METHODS}

We report an IRB-approved retrospective study of adult patients with active intravenous drug use (IVDU) admitted to Wake Forest Baptist Medical Center between January 1, 2012, and May 21, 2018, with a primary diagnosis of possible or definite IE. ${ }^{4}$ Baseline demographics, consulting services and substance abuse resources, antibiotic course, discharge destination, and 1-year readmission and mortality were collected.

Descriptive statistics were used to describe the population and resources provided. A stepwise logistic regression was performed to identify risk factors associated with 1-year readmission.

Prior presentations: Poster presented at the American Society of HealthSystem Pharmacists Midyear Clinical Meeting in December 2019.

Received October 16, 2019

Revised October 25, 2019

Accepted December 6, 2019

Published online January 2, 2020
RESULTS

One hundred thirteen patients were included (Table 1). Fortyfour percent of patients received care coordination services, while consultation to addiction and psychiatric services was provided for $10 \%$ and $11 \%$ of patients, respectively. Thirteen percent of patients were initiated on MAT during admission, while $6 \%$ had an appointment for MAT at discharge. One-year readmission rates were $46 \%$ and 1-year mortality was $22 \%$. Differences in substance abuse resources and characteristics for patients experiencing 1-year readmission or mortality are noted in Table 2. Discharge destination, receiving substance abuse resources, and completing antibiotics while hospitalized were identified for inclusion in the univariate regression analysis. However, no factors were associated with 1-year readmission.

\section{DISCUSSION}

Consistent with previous smaller studies, use of substance abuse resources during inpatient DUA-IE treatment was sparse. ${ }^{2,5}$ Services provided by care coordination, including educational materials, addiction treatment center referrals, and outpatient appointments, were the most employed resources. Although utilized to a lesser degree, acute pain, psychiatry, and addiction counseling service consults were also observed. The infrequent use of resources is particularly concerning. All published research has been conducted in tertiary academic medical centers, where consult and referral services are likely more abundant. This underscores the need for massive coordination efforts for substance use disorder treatment in urban and rural areas alike.

In our study, MAT was initiated in less than $15 \%$ of encounters, with fewer prescriptions and follow-up appointments at discharge, despite most providers documenting IVDU on admission and discharge. However, this is still higher than prior reports of $7.8 \%$ of patients with MAT at discharge. ${ }^{2}$ The low initiation rate is not unexpected considering the minimal engagement of the aforementioned services traditionally responsible for prescribing therapy. The lack of resources may be attributable to providers' unfamiliarity with 
Table 1 Patient Characteristics $(n=113)$

\begin{tabular}{|c|c|}
\hline \multicolumn{2}{|l|}{ Patient characteristic } \\
\hline Age (years), median [IQR] & $31[25-42]$ \\
\hline \multicolumn{2}{|l|}{ Race, $n(\%)$} \\
\hline Caucasian & $105(93)$ \\
\hline African American & $6(5)$ \\
\hline Other & $2(2)$ \\
\hline Male, $n(\%)$ & $61(54)$ \\
\hline \multicolumn{2}{|l|}{ HIV status, $n(\%)$} \\
\hline Positive & $3(3)$ \\
\hline Negative & $104(92)$ \\
\hline Unknown & $6(5)$ \\
\hline Hepatitis B positive, $n(\%)$ & $8(7)$ \\
\hline \multicolumn{2}{|l|}{ Hepatitis C status, $n(\%)$} \\
\hline Positive & $91(80)$ \\
\hline Negative & 19 (17) \\
\hline Unknown & $3(3)$ \\
\hline \multicolumn{2}{|l|}{ Payer source, $n(\%)$} \\
\hline Uninsured & $60(53)$ \\
\hline Medicaid & $33(29)$ \\
\hline IVDU documented on admission problem list, $n(\%)$ & $79(70)$ \\
\hline \multicolumn{2}{|l|}{$\operatorname{Drug}(\mathrm{s})$ of abuse documented on admission, $n(\%)$} \\
\hline Amphetamines & $23(20)$ \\
\hline Barbiturates & $1(1)$ \\
\hline Benzodiazepines & $26(23)$ \\
\hline Cocaine & $21(18)$ \\
\hline Heroin or opioids & $42(37)$ \\
\hline Cannabinoids & 19 (17) \\
\hline Unknown & $2(2)$ \\
\hline Multiple substances abused, $n(\%)$ & $65(58)$ \\
\hline \multicolumn{2}{|l|}{ Resources provided during admission, $n(\%)$} \\
\hline Acute pain service consult & $13(12)$ \\
\hline Addiction service consult & $11(10)$ \\
\hline Cardiothoracic surgery consult & $86(76)$ \\
\hline Care coordination services (case manager & 49 (44) \\
\hline \multicolumn{2}{|l|}{ and/or social worker) } \\
\hline Psychiatry consult & $12(11)$ \\
\hline Antibiotics completed during hospitalization, $n(\%)$ & 17 (15) \\
\hline \multicolumn{2}{|l|}{ Medication-assisted treatment } \\
\hline Inpatient use, $n(\%)$ & $15(13)$ \\
\hline Buprenorphine & $5(25)$ \\
\hline Buprenorphine/naloxone & $0(0)$ \\
\hline Methadone & $15(75)$ \\
\hline Prescription provided on discharge, $n(\%)$ & $9(8)$ \\
\hline Day supply provided, average & 15 \\
\hline Appointment made for MAT on discharge, $n(\%)$ & $7(6)$ \\
\hline \multicolumn{2}{|l|}{ Discharge destination, $n(\%)$} \\
\hline Home & $28(25)$ \\
\hline Facility & $17(15)$ \\
\hline Against medical advice & $15(13)$ \\
\hline Outside hospital & $38(34)$ \\
\hline Inpatient mortality & $15(13)$ \\
\hline IVDU documented on discharge summary, $n(\%)$ & $111(98)$ \\
\hline $\begin{array}{l}\text { Previous hospital encounter for substance } \\
\text { abuse-related problem, } n(\%)\end{array}$ & $24(21)$ \\
\hline \multicolumn{2}{|l|}{ Resources provided at previous encounter, $n(\%)$} \\
\hline Acute pain service consult & $6(5)$ \\
\hline Addiction service consult & $1(0.8)$ \\
\hline Cardiothoracic surgery consult & $6(5)$ \\
\hline Care coordination services & $9(8)$ \\
\hline MAT prescribed & $3(2.6)$ \\
\hline Psychiatry consult & $5(4.4)$ \\
\hline Readmission within 1 year after discharge, $n(\%)$ & $52(46)$ \\
\hline IVDU documented on readmission, $n(\%)$ & $34(66)$ \\
\hline Days to first readmission, median [IQR] & $37[5.25-$ \\
\hline Mortality within 1 year after discharge, $n(\%)$ & $25(22)$ \\
\hline
\end{tabular}

IVDU, intravenous drug use; MAT, medication-assisted treatment

addiction treatment, reluctance to initiate treatment in the inpatient setting, or stigma surrounding addiction.

We report the findings of the largest retrospective analysis of DUA-IE and addiction resources to date. Our findings share several similarities with published reports. In a similar cohort,
Table 2 Substance Abuse Resources and Characteristics for Patients Experiencing 1-Year Readmission or Mortality

\begin{tabular}{|c|c|c|}
\hline & $\begin{array}{l}1 \text {-year } \\
\text { readmission } \\
(n=52)\end{array}$ & $\begin{array}{l}\text { 1-year } \\
\text { mortality } \\
(n=25)\end{array}$ \\
\hline History of IE prior to admission, $n(\%)$ & $12(23)$ & $7(28)$ \\
\hline \multicolumn{3}{|l|}{ Time of last IVDU, $n(\%)$} \\
\hline$<1$ week & $39(75)$ & $18(72)$ \\
\hline $1-2$ week & $1(2)$ & $1(4)$ \\
\hline $2-3$ week & $3(6)$ & $2(8)$ \\
\hline 3-4 week & $3(6)$ & $3(12)$ \\
\hline$>4$ week & $6(11)$ & $1(4)$ \\
\hline \multicolumn{3}{|l|}{$\begin{array}{l}\text { Resources provided during admission, } n \\
(\%)\end{array}$} \\
\hline Acute pain service consult & $6(11.5)$ & $3(12)$ \\
\hline Addiction service consult & $5(9.6)$ & $0(0)$ \\
\hline Cardiothoracic surgery consult & $32(61)$ & $20(80)$ \\
\hline Care coordination services & $24(46)$ & $6(24)$ \\
\hline Psychiatry consult & $7(13.5)$ & $0(0)$ \\
\hline $\begin{array}{l}\text { Antibiotics completed during admission, } \\
n(\%)\end{array}$ & $5(9.6)$ & $1(4)$ \\
\hline Inpatient MAT use, $n(\%)$ & $10(19)$ & $5(20)$ \\
\hline $\begin{array}{l}\text { Prescription for MAT on discharge, } n \\
(\%)\end{array}$ & $3(6)$ & $0(0)$ \\
\hline $\begin{array}{l}\text { Appointment for MAT on discharge, } n \\
(\%)\end{array}$ & $4(7.6)$ & $2(8)$ \\
\hline \multicolumn{3}{|l|}{ Discharge destination, $n(\%)$} \\
\hline Home & $11(21)$ & $3(12)$ \\
\hline Facility & $11(21)$ & $3(12)$ \\
\hline Against medical advice & $12(23)$ & $1(4)$ \\
\hline Outside hospital & $18(35)$ & $3(12)$ \\
\hline Death & $0(0)$ & $15(60)$ \\
\hline
\end{tabular}

IE, infective endocarditis; IVDU, intravenous drug use; MAT, medication-assisted treatment

Gray et al. reported only $8 \%$ of patients were provided with pain management, psychiatry, or chronic pain services. ${ }^{5} \mathrm{Sim}-$ ilar to readmissions reported by Rosenthal et al., nearly onehalf of our study population was readmitted within 1 year, with two-thirds of those patients reporting continued IVDU. ${ }^{2}$ This is particularly concerning considering the increased treatment costs of DUA-IE compared with non-DUA-IE and the high proportion of Medicaid and uninsured patients in our study. ${ }^{5}$ However, we are the first to conduct a regression analysis for factors associated with a reduction in readmission. Interestingly, no factors impacted 1-year readmission. This could be due to the sparsity of services offered and high rate of readmissions in the DUA-IE population.

Our analysis supports the continued effort to increase awareness of addiction resources for DUA-IE patients. As front-line practitioners, internists and hospitalists are uniquely positioned to facilitate development of robust inpatient intervention programs and promote resource utilization in patients with DUA-IE. Future analysis should continue to evaluate the association of resource utilization and outcomes in this critical patient population.

\section{Acknowledgments:}

Contributors: No additional contributors to report.

Corresponding Author: Alexandra E. Mihm, PharmD; Department of Pharmacy, Wake Forest Baptist Medical Center, Winston-Salem, NC 27157, USA (e-mail: aefoster@wakehealth.edu). 


\section{Compliance with Ethical Standards:}

Conflict of Interest: The authors declare that they do not have a conflict of interest.

\section{REFERENCES}

1. Schranz AJ, Fleischauer A, Chu VH, Wu LT, Rosen DL. Trends in drug use-associated infective endocarditis and heart valve surgery, 2007 to 2017. Ann Intern Med. 2019;170(1):31-40.

2. Rosenthal ES, Karchmer AW, Theisen-Toupal J, Castillo RA, Rowley CF. Suboptimal addiction interventions for patients hospitalized with injection drug use-associated infective endocarditis. Am J Med. 2016;129(5):481-485.
3. Bates MC, Annie F, Jha A, Kerns F. Increasing incidence of IV-drug use associated endocarditis in southern West Virginia and potential economic impact. Clin Cardiol. 2019;42(4):432-437.

4. Li JS, Sexton DJ, Mick N, et al. Proposed modifications to the Duke criteria for the diagnosis of infective endocarditis. Clin Infect Dis. 2000;30(4):633-638

5. Gray ME, Rogawski McQuade ET, Scheld WM, Dillingham RA. Rising rates of injection drug use associated infective endocarditis in Virginia with missed opportunities for addiction treatment referral: a retrospective cohort study. BMC Infect Dis. 2018;18(1):532.

Publisher's Note Springer Nature remains neutral with regard to jurisdictional claims in published maps and institutional affiliations. 